\section{Dentists slam lack of progress in 'war on sugar'}

$\mathrm{T}$ he British Dental Association has urged ministers to turn the page on voluntary action with the food industry, as a new report from Public Health England indicates minimal progress to reduce sugar levels in food, with many food categories showing 'little or no reduction.'

Data from the government's flagship sugar reduction programme show the food industry has cut barely $3 \%$ of sugar from products bought in shops and supermarkets over the last four years.

Dentists have pointed to the success of mandatory action through the sugar levy, which has seen a $44 \%$ fall in the sugar levels is soft drinks since 2015, with many companies taking out sugar to avoid exposure to the tax.

Tooth decay remains the number one reason for hospital admissions among young children, and oral health inequalities are expected to widen further, driven by unprecedented access problems, the suspension of public health programmes, and sugar-laden lockdown diets.

BDA Chair Eddie Crouch said: 'Britain is losing the war on sugar because Ministers remain unwilling to really put up a fight.

'Voluntary action from industry on reformulation is making next to no headway. We need a real sense of urgency, wedded to mandatory targets.

'COVID-19 needs to focus minds on the need for sustained action on preventable diseases like tooth decay and obesity. Hardwon gains will only slip into reverse as lockdown diets take their toll'.

Responding to the report, Cllr Ian Hudspeth, Chairman of the Local Government Association's Community Wellbeing Board, added: 'It is encouraging to see sugar reduction in some food and drink, including a $44 \%$ fall in sugary drinks since the Soft Drinks Industry Levy was introduced, but it is clear more needs to be done faster if we are to tackle childhood obesity head-on.

'It is vital that councils are able to decide how the hundreds of millions of pounds raised from the levy is invested, to ensure that our children get the greatest start in life.

'Councils are uniquely placed given their links to local health, leisure, community and voluntary services, as well as schools to intervene earlier and ensure children stay healthy, active and develop good eating habits into adulthood.

'This includes targeting those areas with the greatest need, such as with oral health programmes, weight management services, exercise referral schemes and offering free or reduced-cost sport.

'This in turn will lead to less pressure on our already overstretched health and care services, saving the country much more from obesity-related treatment in future.'
FGDP(UK) and CGDent update COVID-19

\section{guidance synopsis}

The Faculty of General Dental Practice UK and College of General Dentistry have published an updated synopsis of their guidance on the implications of COVID-19 for the safe management of general dental practice. The synopsis highlights key recommendations at each step of the patient journey, and supports dental professionals to take a risk-based approach to providing safe care regardless of the national COVID-19 threat level.

The new version reflects the recentlyrevised guidance, which includes updated and additional recommendations on fallow periods, air ventilation, the 3 in 1 syringe, dental headpieces, air cleaners, decontamination, the protection of vulnerable staff, and the relevance of the $\mathrm{R}$ number and prevalence rate. It is available at https://www.fgdp.org.uk/implicationsCOVID-19-19-safe-management-generaldental-practice-practical-guide and https://cgdent.uk/standards-guidance.

\section{England: Contract uplifts confirmed}

Following consultation with the BDA, the Department of Health and Social Care has confirmed that contracts will be uplifted by 2.5 per cent in England. The uplift will be paid in November and backdated to 1 April.

As we stressed at the time the

Chancellor announced his deal back in July, an above inflation award represents a bare minimum any government can offer NHS workers. This uplift does not begin to cover the huge increases in expenses practices have faced with PPE and meeting new cross-infection guidelines.

Foundation dentist salaries will be updated by 2.8 per cent, as will Educational Supervisors' grants. Yet again FD service costs have been frozen, which we have strongly objected to. 